\title{
Clinical profile of pediatric patients with cerebral palsy
}

\author{
Sanjeev Gupta S. ${ }^{1}$, Sanjeev Gupta P. ${ }^{2 *}$ \\ DOI: https://doi.org/10.17511/ijpr.2020.i05.01 \\ 1 Saroj Sanjeev Gupta, Assistant professor, Department of Paediatrics, Gujarat Adani Institute of Medical Science, Kutch, Gujarat, India. \\ 2* Pranav Sanjeev Gupta, Third Year Post-graduate Student, Department of Medicine, Geetanjali Medical College, Udaipur, Rajasthan, India.
}

\begin{abstract}
Background and Aim: Cerebral Palsy (CP) describes a group of permanent disorders of the development of movement and posture, causing activity limitation, that is attributed to nonprogressive disturbances that occurred in the developing fetal or infant brain. Hence the present study was planned with the sole objective to study the clinical profile of patients of cerebral palsy and to assess the spectrum of functional disability.Materials and Methods: A total of 100 consecutive children diagnosed as cerebral palsy attending the pediatric department and Rehabilitation center were included in the study. Participants were examined forbehavioral problems like Pervasive Developmental Disorders (PDD) and ADHD. Complete evaluation of a child with CP included an assessment of associated deficits like vision, speech and hearing, oromotor evaluation, epilepsy, and cognitive functioning.Results:Out of 1000 cases studied, spastic cerebral palsy was the commonest physiological type of cerebral palsy (82\%). atonic, athetoid, and dystonic types formed the rest of the $18 \%$ of cases. Among the spastic group, quadriplegia was the commonest topographical type $(48 \%)$ followed by diplegia (24\%). The study showed $96 \%$ of patients were mentally retarded. In the study, $48 \%$ ofchildren with CP had a seizure disorder.Conclusion: Spastic cerebral palsy was the commonest clinical type of cerebral palsy withquadriplegia being the most common topographical type of spastic cerebral palsyfollowed by diplegia as observed in this study. The prevalenceof behavioral problems like autism spectrum disorder and ADHD in the clinical sampleof children with CP was found to be $10 \%$.PDD is not rare in CP and should be considered in patients with other comorbid conditions.
\end{abstract}

Keywords: Cerebral Palsy, Autism, ADHD, Seizures

\section{Corresponding Author}

Pranav Sanjeev Gupta, Third Year Post-graduate Student, Department of Medicine, Geetanjali Medical College, Udaipur, Rajasthan, India. Email: saroj77gupta@gmail.com

\section{How to Cite this Article}

Gupta SS, Gupta PS. Clinical profile of pediatric patients with cerebral palsy. Pediatric Rev Int J Pediatr Res. 2020;7(5):194-198.

Available From

https://pediatrics.medresearch.in/index.php/ijpr/arti cle/view/601
To Browse

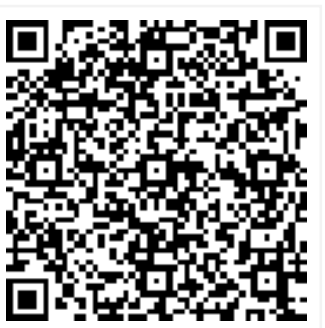

Manuscript Received 2020-06-06

Conflict of Interest No
Review Round 1 2020-06-15

Funding $\mathrm{Nil}$

Review Round 2
2020-06-20
Ethical Approval
Yes

Review Round 3

Accepted 2020-06-25

Plagiarism $\mathbf{X}$-checker $7 \%$

(c) 2020 by Saroj Sanjeev Gupta, Pranav Sanjeev Gupta and Published by Siddharth Health Research and Social Welfare Society. This is an Open Access article licensed under a Creative Commons Attribution 4.0 International License https://creativecommons.org/licenses/by/4.0/ unported [CC BY 4.0]. 


\section{Introduction}

A cerebral palsy is a group of disorders that affect movement and muscle tone or posture. It's caused by damage that occurs to the immature brain as it develops, most often before birth. Signs and symptoms appear during infancy or preschool years. In general, cerebral palsy causes impaired movement associated with abnormal reflexes, floppiness or rigidity of the limbs and trunk, abnormal posture, involuntary movements, unsteady walking, or some combination of these $[1,2]$.

Cerebral palsy (CP) is a problem that affects muscle tone, movement, and motor skills. It hinders the body's ability to move in a coordinated and purposeful way. It also can affect other body functions that involve motor skills and muscles, like breathing, bladder and bowel control, eating, and talking [3]. CP often is caused by brain damage that happens before or during a baby's birth, or during the first 3-to-5 years of a child's life.

Brain damage also can lead to other issues, like sight, hearing, and learning problems. Ravn et al. reported the total $\mathrm{CP}$ birth prevalence has been significantly decreasing since the birth period 19831986 with 3.0 per 1000 live births until the period 1995-1998 with 2.1 per 1000 live births [4].

The overall decrease was seen in preterm infants ( $<31$ weeks) as well as in term infants and despite a simultaneous fall in perinatal and early neonatal mortality in the preterm group. Analyzing the subtypes of $\mathrm{CP}$, a significant increase in the numbers as well as the rate of unilateral CP with a simultaneous fall in the numbers as well as the rate of bilateral CP $[5,6]$.

Complete evaluation of a child with $\mathrm{CP}$, therefore, should include an assessment of associated deficits such as vision, speech, hearing, sensory profile, oromotor evaluation, epilepsy, and cognitive functioning. $\mathrm{CP}$ is a chronic condition with a considerable impact on affected individuals. Early diagnosis and comprehensive management with a multidisciplinary approach involving developmental pediatrician, neurologist, orthopedic surgeon, speech and language therapist, physio, and occupational therapist are required for satisfactory management of a child with CP [7].

The upper limit for brain injury is not uniformly defined but is generally taken as 3-5 years of age.
The diagnosis of cerebral palsy should not be made till the age of $2 y r s$ because some minor tone abnormalities which can be present during infancy can disappear as the child grows. But the diagnosis of cerebral palsy can be entertained in children less than 2years of age if the child is severely involved or has supporting evidence (e.g. neuroimaging studies). Although, cerebral palsy is a disease with abnormalities in tone and posture, predominantly, the children with cerebral palsy would expect to have damage to other parts of the brain as well and this may be manifest as epilepsy, specifically learning disabilities, speech problems or mental handicap [8].

Since CP is a continuing problem, it is important to study and explore the causes and newer aspects of the condition for proper understanding and management. In high-income countries, CP registers have made substantial contributions to our understanding of CP. However, in low- and middleincome countries, there are gaps in knowledge especially in spheres of epidemiological research, intervention, and service utilization. To date, there is no exact database of the CP patients in India. Furthermore, there is a lack of large scale community studies estimating the exact prevalence of CP in India. Hence the present study was planned with the sole objective to study the clinical profile of patients of cerebral palsy and to assess the spectrum of functional disability.

\section{Materials and Methods}

The present study was done in the pediatric department in the medical institute. The present study is the observational study conducted for a period of one year. A total of 100 patients diagnosed with cerebral palsy attending the OPD of the pediatric department were included in the study. All the patients belonged to the age group of upto 12 years. Children with non-central causes of motor deficits and children with the progressive neurological disorder were excluded from the study.

The three essential features were considered for the diagnosis of cerebral palsy: a) Presence of impairment of neurological function, especially voluntary motor activity, b) The disorder is nonprogressive and non-hereditary, c) The disorder is present since birth or early infancy. Cerebral palsy is a clinical diagnosis made by an awareness of risk factors, regulardevelopmental screening of all highrisk babies, and neurological examination. 
As in allmedical conditions, a systematic approach focusing on maternal, obstetric and perinatalhistories, review of developmental milestones, and a thorough neurological examinationand observation of the child in various positions such as supine, prone, sitting, standing, walking and running was made.

$\mathrm{CP}$ is classified based on the type of neuromuscular deficit into (i) spastic (ii) dyskinetic (inclusive of choreo-athetoid and dystonic) (iii) ataxic (iv) hypotonic and ( $v$ ) mixed. Further classification of the type of spastic cerebral palsy depends on thetopography of involvement.Complete evaluation of a child with CP included an assessment of associateddeficits like vision, speech and hearing, oromotor evaluation, epilepsy, and cognitive functioning. Orthopedic evaluation, psychiatric assessment.

EEG: is indicated in children presenting with seizures, history of neonatalseizures, underlying malformation/ lesion of the brain found on neuroimaging, and during follow-up.

Statistical Methods: Descriptive statistical analysis has been carried out in thepresent study. Results on continuous measurements are presented on Mean $\pm S D($ Min-Max) and results on categorical measurements are presented in Number (\%).Significance is assessed at a $5 \%$ level of significance. The following assumptions on data aremade, Assumptions: 1. Dependent variables should be normally distributed,2. Samples drawn from the population should be random, Cases of the samplesshould be independent.

\section{Results}

The present clinical study included 100 children diagnosed with cerebral palsy, to study the clinical profile of patients. All the children were upto the age of 12 years. Maximum children belong to the age group of $2-6$ years, the next number was in the age group of more than 6 years. The male predominated as compared to females. More than half of the patients were male.

Owing to the clinical types of cerebral palsy, the most common physiological type of cerebral palsy is the spastic cerebral palsy. Among the spastic group, the subtypes present were quadriplegia, diplegia, hemiplegia, and double hemiplegia. Maximum patients were of spastic quadriplegia. The patients were divided as per the functional classification, type I to type IV.
Majority of the patients belonged to class III. The nutritional status was assessed in the following table. As per the analysis majority of the children were malnourished. A total of ninety percent were malnourished. Of the total 90 children who were malnourished, the majority of the children belonged to type I malnourishment. About 56 children belong to grade I, in grade II malnutrition there were 30 children, 4 children where categorized in grade III whereas normal nutritional level was found in 10 children.

Table-1: nutritional status of the children.

\begin{tabular}{|l|l|l|l|}
\hline \multicolumn{1}{|c|}{ Nutrition status } & \multicolumn{1}{c|}{ Males } & \multicolumn{1}{c|}{ Females } & \multicolumn{1}{c|}{ Total } \\
\hline Normal & \multicolumn{1}{|l|}{} & 2 & 10 \\
\hline Abnormal & 24 & 22 & 2 \\
\hline Grade I & 36 & 8 & 2 \\
Grade II & 56 & 30 & 4 \\
Grade II & 56 & 44 & 100 \\
\hline Total 0 &
\end{tabular}

When the head circumference was analyzed in all the children, normal head circumference was found in 22 children, whereas microcephaly was analyzed in 78 children. The study showed $96 \%$ of patients had mental retardation, among them; borderline $(12 \%)$, mild $(20 \%)$, moderate $(18 \%)$, severe $(13 \%)$, and profound $(10 \%)$. When the seizure disorder was analyzed; 48 children had a history of cerebral seizures. Among them, 50\% were generalized tonic-clonic seizures, myoclonic seizure $(29 \%)$, febrile seizure (4\% refractory seizure $(8 \%)$ and status epilepticus (8\%).The present study showed that $10 \%$ of the patients had behavioral problems in the formof pervasive developmental disorder autism and ADHD. Autism was found in 8 children and 2 children had ADHD.

Table-2: Type of cerebral seizures.

\begin{tabular}{|l|l|}
\hline \multicolumn{1}{|c|}{ Type of seizures } & \multicolumn{1}{c|}{ Number of children $(\mathbf{n}=\mathbf{4 8})$} \\
\hline GTCS & 24 \\
\hline Myoclonic & 14 \\
\hline Refractory & 4 \\
\hline Status epilepticus & 4 \\
\hline Febrile seizures & 2 \\
\hline
\end{tabular}

Type-3: Pervasive development disorders (PDD).

\begin{tabular}{|l|l|l|}
\hline \multicolumn{1}{|c|}{ PDD } & \multicolumn{1}{c|}{ Male } & \multicolumn{1}{l|}{ Female } \\
\hline Normal & 48 & 42 \\
\hline Abnormal & 6 & 2 \\
\hline Autism & 2 & 0 \\
ADHD & 56 & 44 \\
\hline Total & 6 & \\
\hline
\end{tabular}




\section{Discussion}

The prevalence and pattern of $\mathrm{CP}$ vary between different geographical regions probably due to different etiological factors and different classifications used. A number of European countries have reported a significant decrease in the prevalence and severity of CP subtypes and associated impairments, most likely explained by advancements in obstetric and newborn care. In Norway, the prevalence of CP decreased from 2.62 per 1000 live births in 1999 to 1.89 in 2010 [7]. In Slovenian children, the total prevalence of $\mathrm{CP}$ per 1000 live births fell significantly from 3.3 in 1981 to 2.3 in 1990 [8].

The present study was done in the medical institute in the hospital center with multidisciplinary specialties. The present study was done in the OPD of the pediatric department of the tertiary care hospital. In this study, the maximum number of patients $(52 \%)$ were $2-5$ years of age group followed by more than 5 years (24\%) and less than 2 years (24\%). A study done by Shinghi PD et al [9] showed $50.2 \%$ in less than 2 years of age, $33 \%$ in 2-5 years of age, and $18 \%$ more than 5 years. Another study done by Sharma et al [10] found similar findings wherein $51.65 \%$ was in the age group of 1-5 years. The study showed male babies were predominant group (55\%).

The majority were grade I malnourished (56\%) and grade II malnutrition (30\%), whereas $4 \%$ had grade III malnutrition. $10 \%$ of patients had normal nutritional status as compared to study by Singhi PD et al [9] in which $50.6 \%$ were malnourished and $28.1 \%$ were severely malnourished. The majority were in class $3(52 \%)$, followed by class $2(34 \%)$. Only $8 \%$ were in class 4 and $6 \%$ had class 1 level of gross motor functional ability. None were fully normal.

Spastic cerebral palsy was the commonest physiological type of cerebral palsy $(82 \%)$ followed by athetoid type (10\%). Atonic ( $4 \%$ ) and dystonic (4\%) types formed the rest of the cases. In this study among the spastic group, quadriplegias were $48 \%$, diplegia $24 \%$, hemiplegia $6 \%$, monoplegia $2 \%$, and double hemiplegia $2 \%$. It is comparable to other studies done in which spastic cerebral palsy was the commonest type; Singhi PD et al [9] showed $(70 \%)$, Srivatsava VK et al showed $(91.4 \%)$ and SahuSuvanand et al had (88\%)cases in their study.
$78 \%$ of children had microcephaly and only $22 \%$ had normal head circumference, whereas a study by Singhi Pratibha D et al showed $(88.6 \%)$ with microcephaly. This study showed $96 \%$ of patients had mental retardation, among them borderline $(12 \%)$, mild $(20 \%)$, moderate $(18 \%)$, severe $(13 \%)$, and profound $(10 \%)$. Children with spastic quadriplegia have a greater degree of cognitive impairment than children with spastic hemiplegia. The study by P. D, Singhi et al in a study in Indiareported the prevalence of mental retardation $72.5 \%$, Srivatsava VK et al reported the prevalence of mental retardation $47.2 \%$. Assessment of impairment in communication was the most difficult. Because ofbilateral corticobulbar dysfunction in many CP syndromes, anarthritic or dysarthric speech caused by oromotor dysfunction is common [11]. Here mutism was considered as an autisticfeature when it was accompanied by no compensatory alternative modes ofcommunication such as gestures. Most of the nonverbal children were reported asbehaving as if they could not hear, although hearing assessments revealed no problems. These children did not respond to their names being called but were responsive whenoffered something that they wanted. They did not point or gaze at the objects that theywanted spontaneously. It is important to note that motor and cognitive impairmentsshould be taken into consideration when PDD is being assessed in children with $C P$ in order not to over-diagnose.The limitation of this study is the study cannot generalize to the whole population.

\section{Conclusion}

This study was done to study the clinical profile of cerebral palsy. Spastic cerebralpalsy was the commonest clinical type of cerebral palsy with quadriplegia being the mostcommon topographical type of spastic cerebral palsy followed by diplegia as observed inthis study. The prevalence of behavioral problems likeautism spectrum disorder and ADHD in the clinical sample of children with $\mathrm{CP}$ was found to be $10 \%$. PDD is not rare in CP and should be considered in patients with othercomorbid conditions.

\section{What does the study add to the existing knowledge?}

The clinical spectrum of CP in our country, thus, differs from that reported in western countries due to perinatal and postnatal morbidities such as birth 
Asphyxia, CNS infection, bilirubin encephalopathy, and hypoglycemia. Furthermore, the percentage of children who have undergone visual and hearing assessment and undergoing rehabilitation is quite low. Timely diagnosis and initiation of appropriate management should be ensured to decrease the incidence of $\mathrm{CP}$ and associated disabilities or handicaps in the future.

\section{Author's contribution}

Dr. Saroj Sanjeev Guptaformulated the aims and objectives with study design and helped in data collection from the medical record department.

Dr. Pranav Sanjeev Guptacontributed to the preparation of the manuscript and data analysis.

\section{Reference}

01. Panteliadis CP, Hagel C, Karch D, Heinemann K. Cerebral palsy- a lifelong challenge asks for early intervention. Open Neurol J. 2015;9;4552.

doi: $10.2174 / 1874205 \times 01509010045$ [Crossref]

02. Lin JP. The assessment and management of hypertonus in cerebral palsy- a physiological atlas (road map'). Clinics in developmental Medicine. 2004;85-104.

[Crossref]

03. Uysal SA, Düger T. Motor control and sensorymotor integration of human movement. Comparative Kinesiology of the Human BodyElsevier. 2020;443-452.

[Crossref]

04. Ravn SH, Flachs EM, Uldall P. Cerebral palsy in eastern Denmark: declining birth prevalence but increasing numbers of unilateral cerebral palsy in birth year period 1986-1998. Eur JPaediatr Neurol. 2010;14(3)214-218.

doi: 10.1016/j.ejpn.2009.06.001 [Crossref]

05. Li Y. Role of water channels in kidney and lung. Institutionen för kvinnors och barns hälsa/Department of Women's and Children's Health. 2009.

[Crossref]

06. Lyons-Ruth K, Zeanah CH, Benoit D, Madigan S, Mills-Koonce W. Disorder and risk for disorder during infancy and toddlerhood. Child Psychopathol. 2003;2;589-631.

[Crossref]
07. Sankar C, Mundkur N. Cerebral palsy-definition, classification, etiology and early diagnosis. Indian JPediatr. 2005;72(10)865-868.

doi: $10.1007 /$ bf02731117 [Crossref]

08. O'Shea TM. Diagnosis, treatment, and prevention of cerebral palsy in near-term/term infants. Clin Obstet Gynecol. 2008;51(4):816828.

doi: $10.1097 \% 2 F G R F .0 b 013 e 3181870 b a 7$ [Crossref]

09. Singhi PD, Ray M, Suri G. Clinical spectrum of cerebral palsy in North India-an analysis of 1000 cases. J Trop Pediatr. 2002;48(3)162-166. doi: $10.1093 /$ tropej/48.3.162 [Crossref]

10. Sharma P, Sharma U, Kabra A. Cerebral PalsyClinical profile and predisposing factors. Indian Pediatr. 1999,36(10)1038-1042.

[Crossref]

11. Russman BS, Ashwal S. Evaluation of the child with cerebral palsy. Seminars in pediatric Neurology- Elsevier. 2004;47-57.

[Crossref] 